Dossiê: Narrativas

\title{
Memória de idosos \\ As narrativas em diferentes espaços de interação social
}

\author{
Elderly memories \\ Narratives in different spaces of social interaction \\ Ana Keila Mosca Pinezi
Marilda Aparecida de Menezes
Alexandre Soares Cavalcante*
}

Resumo: Este artigo tem como objetivo analisar as narrativas de memória construídas por idosos que residem nos bairros Bangu e Santa Terezinha, onde situa-se a Universidade Federal do ABC, campus Santo André, SP. Esses idosos participaram de um projeto de extensão desenvolvido por uma equipe dessa universidade, cujo objetivo foi de propiciar um espaço de construção de memória por meio de conversas e do acesso a tecnologias informacionais e comunicacionais. Pretendemos analisar como, nesses espaços interativos, emergem diferentes conteúdos e formas de narrar, bem como expressões do corpo e do imaginário diante dos equipamentos digitais e de sua manipulação. Por entre fotografias de filhos e netos, da mocidade e da idade "madura", do café e quitutes caseiros no ambiente universitário, esses idosos tornaram os equipamentos de informática em uma experiência de inclusão digital e de expressão da memória, e os espaços interativos foram uma experiência de aproximação entre a memória dos sujeitos que ocupam um dos bairros mais antigos da cidade, Santa Terezinha, e a memória dos jovens universitários.

Palavras-chave: Memória de idosos. Narrativas. Santo André.

Abstract: This article aims to analyze narratives built by the memory work of elderlies who live in Bangu and Santa Terezinha neighborhoods, in Santo André campus, São Paulo, where the Federal University of ABC has a campus. These elderlies take part on an extension project which had the aim of offering a memory building space through

* Ana Keila Mosca Pinezi é doutora em Ciências pela Universidade de São Paulo (Brasil), professora adjunta do PPG em Ciências Humanas e Sociais da Universidade Federal do ABC (UFABC) em Santo André, SP, Brasil<keipinezi@gmail.com>. Marilda Aparecida de Menezes é doutora em Sociologia pela Universidade de Machester (Reino Unido), professora visitante nacional sênior no PPG em Ciências Humanas e Sociais da UFABC < menezesmarilda@gmail. com>. Alexandre Soares Cavalcante é mestrando no PPG em Ciências Humanas e Sociais da UFABC <ale.soares726@gmail.com>.

\begin{tabular}{|c|c|c|c|c|c|}
\hline Civitas & Porto Alegre & v. 14 & n. 2 & p. 341-358 & maio-ago. 2014 \\
\hline
\end{tabular}

A matéria publicada neste periódico é licenciada sob forma de uma 
conversations and access to communication and information technologies. This article intends to analyze the different contents and forms of narration, as well as expressions of body and imaginary arise in these interactive space in front of digital equipments. Among photographs of children and grandchildren, of their youth and in the "mature" age, coffee and homemade delicacies in the university environment, these seniors transformed the contact experience with the computer equipment in digital inclusion and expression spaces for the memory. These interactive experience approached the memory of the inhabitants of the oldest neighborhoods of the city, Santa Terezinha, and the memory of the young students.

Keywords: Elderly Memories. Narratives. Santo André.

\section{Introdução}

As reflexões aqui propostas, tangenciando as narrativas de memórias de idosos frente ao uso das tecnologias digitais de informação e comunicação, são desdobramentos de um projeto de extensão realizado durante o ano de 2010 na Universidade Federal do ABC, campus Santo André, localizada na região metropolitana de São Paulo. O projeto fora concebido a partir da problematização dos impactos oriundos da instalação de uma universidade federal na região do bairro Bangu, em Santo André, município do $\mathrm{ABC}$ Paulista.

Estes impactos não devem ser compreendidos somente em termos materiais e/ou econômicos. Pelo contrário, a perspectiva da qual se partiu é a de que as modificações oriundas da instalação da universidade impactam também nas relações que diferentes sujeitos travam com o espaço da cidade, de modo que as narrativas e memórias construídas em torno destes espaços, geográficos e simbólicos, encontram-se em contínuo processo de negociação e reformulação. Assim, o projeto também nasceu do desejo de ouvir o que os moradores mais antigos de dois bairros históricos de Santo André tinham a dizer sobre suas memórias no que se referem à cidade e suas transformações no decorrer do tempo e às suas vivências nesse espaço social, marcado por um entrelaçamento entre movimentos e relações familiares e o crescimento da cidade.

O desenvolvimento do projeto se deu em diferentes etapas. Primeiramente, no período de outubro a dezembro de 2009, foram pesquisadas fontes sobre o entorno do bairro onde está localizado o primeiro campus da Universidade Federal do ABC, o bairro Bangu, em Santo André. A partir de pesquisas digitais e em museus da cidade, um panorama das mudanças visuais dos arredores da região pode ser construído, permitindo aos participantes e pesquisadores 
formularem uma contextualização da região. Naquele período, iniciamos a elaboração de um documento acerca da história geral de Santo André e da história específica dos bairros, com sucessivas visitas ao Museu de Santo André para a coleta de documentos e consulta de fotos.

No período de janeiro a fevereiro de 2010 passou-se a abordar os idosos moradores dos dois referidos bairros para que pudessem participar do projeto, dentro da universidade. Trazer idosos para dentro da universidade, idosos esses que não são os professores da instituição, é algo que desafia a percepção tradicional das categorias sociais atreladas à faixa etária e aos espaços pelos quais circulam ou devem circular essas diversas categorias. A noção de idoso foi problematizada entre os integrantes do projeto.

A ideia foi desnaturalizar conceitos fixos, imóveis e monossêmicos sobre a divisão social das faixas etárias. A categoria de idoso pode ser construída a partir de diferentes critérios e demarcadores identitários. As categorias de idade que definem infância, juventude, idoso não são neutras, mas são construções culturais e sociais que atendem a interesses políticos e institucionais e que, portanto, resultam da luta por nomeações e hierarquizações entre os grupos sociais (Bourdieu, 1983). Nesse sentido, a idade de 60 anos como definidora da categoria de idoso ou de terceira idade tem como objetivo definir direitos e deveres para regulamentar a ação de instituições governamentais ou da sociedade civil.

Não foi necessariamente a idade um critério de corte para definir o idoso no nosso projeto, mas a experiência dos moradores mais velhos dos bairros e sua disponibilidade subjetiva em participar no grupo. Consideramos não apenas a faixa etária ou a quantidade de anos vividos para se definir quem é jovem e quem é velho, mas também as experiências e as vivências em determinadas formas de sociabilidade, contextos sociais e processos que mesclam aspectos cognitivos, ambientais e corporais. Juventude e velhice, numa perspectiva histórico-antropológica, são categorias historicamente construídas e tão variáveis e, embora tenhamos nos acostumado a enxergar algumas particularidades próprias em cada uma delas, nosso projeto ajuda a problematizar tais fenômenos como complexos, instáveis, heterogêneos, muito além das caracterizações por faixas etárias.

Os moradores idosos dos Bairros Bangu e Santa Terezinha têm nas suas trajetórias de vida as marcas da região em que vivem. Foram operários e operárias de indústrias, do comércio ou donas de casa. Na fase de vida em que estão aposentados e com filhos já criados, já não fazem mais parte da chamada "população economicamente ativa". No entanto, continuam sendo homens e mulheres ativos e agentes da história no seio de suas famílias, seu bairro, sua 
cidade. Poucos são os espaços de sociabilidades onde possam compartilhar suas angústias, memórias e o prazer da convivência.

Nesse sentido, a proposta do projeto de extensão foi oferecer uma aproximação entre os moradores e a universidade, além de promover uma oportunidade de aprendizado da tecnologia informacional e comunicacional. Através de encontros semanais foram organizadas atividades relacionadas aos usos e construções de memórias individuais e coletivas, dirigidas por um grupo de jovens alunos e professores que se dispuseram, numa perspectiva interdisciplinar, a olhar, ouvir, escrever em torno de práticas compartilhadas num diálogo intergeracional (Oliveira, 2006). Assim, os encontros representaram um espaço de partilha de experiências de vida e de construção de memórias, buscando associar o presente ao passado de suas vidas, as lembranças do espaço, da família, das festas de uma cidade em movimento e constante transformação.

\section{A metodologia dos encontros}

O contato inicial com os homens e mulheres foi realizado a partir de visitas, de casa em casa, conversando com os moradores e explicando do que tratava o projeto. Esses moradores foram questionados se gostariam de participar ou indicar alguém possivelmente interessado em participar do projeto dentro da universidade. Vale ressaltar que, na medida em que as visitas foram realizadas, percebeu-se a necessidade de expandir o projeto para abarcar também os moradores do bairro Santa Terezinha, vizinho do bairro Bangu, e que conta com uma alta presença de moradores idosos, em virtude do histórico de ocupação do local e sua imbricada relação com o desenvolvimento das indústrias na região do $\mathrm{ABC}$, em especial no município de Santo André.

Descobrimos, então, aos poucos, que estes idosos tinham participado ativamente dos primórdios do desenvolvimento da cidade. Viram Santo André, uma cidade bastante próxima do "rural", transformar-se em berço da industrialização tardia brasileira. Arranha-céus e grandes galpões começaram a mudar a paisagem tranquila e interiorana da cidade. Atraídos pela esperança do progresso, pelo desenvolvimento industrial, a cidade recebeu migrantes do Nordeste do país e de vários países, como a Itália e a Alemanha. Não só a paisagem foi mudada como também a composição populacional. Os idosos dos bairros Bangu e Santa Terezinha, então, vivenciaram essas transformações e essa memória nos pareceu muito mais viva que os documentos do museu da cidade.

Os idosos que aceitaram participar do projeto tiveram seus dados (nome, idade, escolaridade, endereço, número de telefone) coletados e, posteriormente, 
foram contatados para a realização do primeiro encontro realizado em $30 \mathrm{de}$ março de 2010. A participação significava a disposição e disponibilidade de ir à universidade uma vez por semana, durante um ano, para lá poder contar as memórias e registrá-las por meio de tecnologias de informação e comunicação, em especial, a internet. Assim, um grupo de idosos respondeu ao nosso convite.

No primeiro encontro recebemos na UFABC cerca de 15 homens e mulheres na faixa de idade entre 65 e 80 anos. Eles entraram receosos, como quem pede "licença" para entrar na casa de um outro desconhecido. Foram recebidos pela equipe do projeto em um dos portões da universidade, que os levou até um laboratório de informática. Ao chegarem lá, eles se surpreenderam que ali faríamos nossas reuniões semanais por entre aquelas máquinas, pois os computadores eram coisa distante deles.

Durante os encontros, realizados semanalmente, durante um ano, os idosos iam à universidade e, no ambiente de um laboratório de informática, lidavam com as tecnologias digitais de comunicação e informação, como computador, escâner, câmera digital, com o auxílio dos estudantes de graduação, bolsistas e voluntários, para que pudessem compreender melhor os usos destas tecnologias, que muitas vezes (re)produzem diversas desigualdades sociais no que tange ao seu acesso e desenvolvimento.

$\mathrm{O}$ encontro iniciava-se às 14 horas, com um intervalo que era acompanhado de quitutes e guloseimas trazidos pelos participantes - os estudantes, professores e os idosos. A primeira parte era dedicada ao trabalho com as tecnologias de informação e a segunda parte era uma roda de conversa sobre suas histórias, suas visões de mundo e como se sentiam mediante o universo das tecnologias, da universidade, da cidade e de sua condição de idoso.

Nas atividades semanais do projeto, os jovens estudantes e professores dialogavam com os idosos para, juntos, trocarem experiências, conhecerem e utilizarem em comum algumas tecnologias de informação e comunicação no espaço da Universidade Federal do ABC. A utilização da internet e de outras formas de comunicação mais recentes, também tomava, aos poucos, lugar no imaginário e na vida desses idosos, conectando-os com a memória que têm das gerações mais recentes de sua família. Ter uma conta de e-mail não era só uma forma a mais de comunicar-se, mas também uma maneira de representar-se de forma surpreendente diante de filhos, netos e bisnetos.

O projeto não definiu uma metodologia específica dos encontros, mas ela foi sendo construída nas interações sociais entre os idosos, estudantes e professores. Como nos ensina Wright Mills (1975), as estratégias metodológicas utilizadas se fundamentaram na sensibilidade, criatividade, imaginação de estudantes e pesquisadores nesse encontro dialógico com os 
idosos. Embora durante a realização dos encontros e espaços de diálogo não fazíamos referência à metodologia como grupo de discussão, entendemos que as formas de diálogo experimentadas nesses encontros se aproximam do que propõe a metodologia dos grupos de discussão conforme nos explica Weller (2010a, p. 56):

Nos grupos de discussão, o pesquisador deve assumir uma postura que Mannheim (1980) definiu como sociogenética ou funcional, ou seja, que busca intervir o mínimo possível, que evita perguntas do tipo "o que" ou "por que", buscando fomentar discussões voltadas para o "como", ou seja, que levem à reflexão e narração de determinadas experiências e não somente à descrição de fatos. O objetivo maior do grupo de discussão é a obtenção de dados que possibilitem a análise do contexto ou do meio social dos entrevistados, assim como de suas visões de mundo ou representações coletivas.

Assim como nos ensina a metodologia dos grupos de discussão, os pesquisadores e estudantes buscaram intervir o mínimo nas interações com os idosos, utilizando-se de estratégias pedagógicas e de comunicação virtual para a construção de um espaço de aprendizado, de discussão, reflexão e de construção de memórias. Lembrar a cidade, na época da juventude, da maturidade e da velhice significava para esses idosos dizer quem são e como construíram suas experiências de trabalho, de família, de escolarização e de lazer.

Os pesquisadores, no caso estudantes e professores, atuaram como mediadores, facilitadores da construção de memória dos idosos. Ao perguntarmos, em uma roda de conversa, o que é ser idoso, o grupo se sentiu bastante estimulado a descrever quais os estereótipos sobre isso e a rebatê-los. Embora estivéssemos ali e nossa observação fosse, sem dúvida, participante, os idosos narraram suas experiências nessa fase de sua vida apontando adequações e inadequações. Eles usavam exemplos do que é ser um "idoso respeitável" e o que é ser um "idoso ridículo".

Nessas narrativas, pudemos perceber a construção da imagem de si mesmo perante o outro, em outros termos, acionavam valores e memórias na construção de suas identidades. A relação entre memórias e identidades foi bem elaborada por Michael Pollak (1989), que compreende a memória como um campo de forças e sua história diversa e conflituosa. O termo "campo de força" usada por Pollack significa lutas de processos e atores sociais na construção de uma memória e da identidade social. A perspectiva teóricometodológica de Pollack reabilita a periferia e o que é marginal na história oficial, assim, não adere à visão de dominação exclusiva de um sobre outro, 
no campo da memória, mas à possibilidade de resistências constantes em um campo de forças materiais e simbólicas. Mesmo que o silêncio seja uma prática social utilizada por muitos indivíduos e grupos, isto não significa dizer que eles são passivos, conformistas, é uma uma forma de protesto mudo.

As noções de "idoso respeitável” ou "idoso ridículo” talvez já estivessem presente no imaginário desses idosos e verbalizadas em espaços da família ou entre amigos, mas não visibilizadas para um público externo à eles. Os estudantes e professores se revelaram como personagens de escuta dos idosos, o que permitiu à eles uma certa liberdade em expressar os seus valores, noções de respeito e de autoimagem.

Embora as narrativas eram, em geral, de consensos sobre as identidades dos idosos, havia discordâncias e concordâncias. A questão de gênero apareceu claramente nessa narrativa. Os homens falaram de como é ser um "velho" aceitável aos padrões e expectativas sociais em termos de suas atividades, de como as limitações físicas do presente devem ser aceitas. Já as mulheres falaram da forma de vestir de uma idosa "adequada" e das que não se vestem adequadamente à sua idade.

A noção de respeito foi, várias vezes, evocada nessa narrativa. $\mathrm{O}$ respeito ao idoso, para eles, tem uma relação direta com o comportamento que devem ter socialmente. No centro da narrativa, esses idosos falavam sobre si, mas também sobre modelos de ser. Em outros termos, ao narrarem sobre si mesmos, estão mobilizando memórias do passado a partir presente para construção de suas identidades. É importante lembrar que essa construção que envolve narrativas e identidades dos idosos situa-se num espaço de interação social com jovens estudantes e pesquisadores, além de serem uma escuta atenta, também, estavam em um outro tempo do ciclo de vida.

Outra situação que pode ser citada aqui aconteceu no momento em que os idosos, cada um em frente a um computador, foram perguntados sobre que lugares do mundo gostariam de conhecer. Em frente a um site de busca, digitaram o nome do país ou cidade. Imagens apareceram e eles, entre si, começaram a apreciar os detalhes dessas imagens. A narrativa, naquele momento, tomou forma de uma espécie de viagem em que um grupo reunido faz uma excursão a algum lugar específico. Na verdade, a narrativa se tornou uma incursão ao mundo de lugares, mas em especial dos lugares e desejos interiores desses idosos que acionaram a memória no sentido de contar desde quando sonham em conhecer esse lugar. Passado e presente se encontraram nessa narrativa e foram compartilhados de forma intensa. As tecnologias de informação e comunicação, algo "destes tempos", tornaram-se uma ponte para a memória construída ao longo da trajetória dos desejos e sonhos. Diálogos, 
especulações surgiram naquele tempo especial, naquela viagem provocada pelas imagens que tocaram os anseios e as possibilidades de realizá-los.

A conexão entre os momentos de interação com as tecnologias digitais de comunicação e informação e os momentos de troca de experiências e histórias de vida foi realizada a partir da criação de um blog na internet, no qual cada um dos participantes podia postar e interagir. Com isso, a noção que, no senso comum, coloca a utilização de tais tecnologias como algo associado às gerações mais jovens pôde ser problematizada e questionada no âmbito do projeto.

\section{Memórias do bairro}

$\mathrm{Na}$ experiência do projeto de extensão com os idosos, o objetivo não era apenas coletar material de pesquisa, mas de construção de um espaço de valorização das narrativas dos idosos e de aproximação entre o saber dos meios informacionais de comunicação e a memória oral. Nesse sentido, os encontros entre idosos, estudantes e professores não produziram propriamente biografias nem uma informação sistemática sobre determinados temas como trabalho, família, religião, mas relatos de fatos da família, de espaços da cidade e de alguns eventos sociais. Isso era a própria metodologia, qual seja a de deixá-los falar o que era relevante para eles, para vermos o que emergia no trabalho da memória (Bosi, 1987).

Nos encontros, os idosos eram convidados a trazer fotos e objetos que para eles tinham significado e que falavam algo sobre suas trajetórias de vida. São objetos de memória, ao apresentá-los ao grupo discorriam sobre o período de sua juventude e sobre as mudanças do espaço urbano, compondo narrativas que dão conta de ressignificá-los e dar uma dimensão afetiva, que ultrapassa o simples registro físico e leva ao registro emocional e simbólico.

Descrevemos alguns espaços dos dois bairros, por meio de fotos do acervo pessoal, da memória oral dos participantes e de textos de outros documentos arquivados no Museu de Santo André.

Um espaço que marca a Vila Santa Terezinha é a Vila Popular, que resulta da "Fundação casa popular" que teve sua construção iniciada em 1947, em um espaço ocupado por uma vacaria. Em 1949, as quase 500 habitações já estavam prontas. Os preços das casas variavam de acordo com a idade do comprador, pois havia um termo que dizia que se o chefe da família morresse, se as mensalidades estivessem em dia e se pelo menos 3 mensalidades já tivessem sido pagas, seus descendentes não precisavam pagar o restante. O comprador precisava ter filhos e ganhava um fogão de ferro a carvão de presente ao comprar uma casa. 


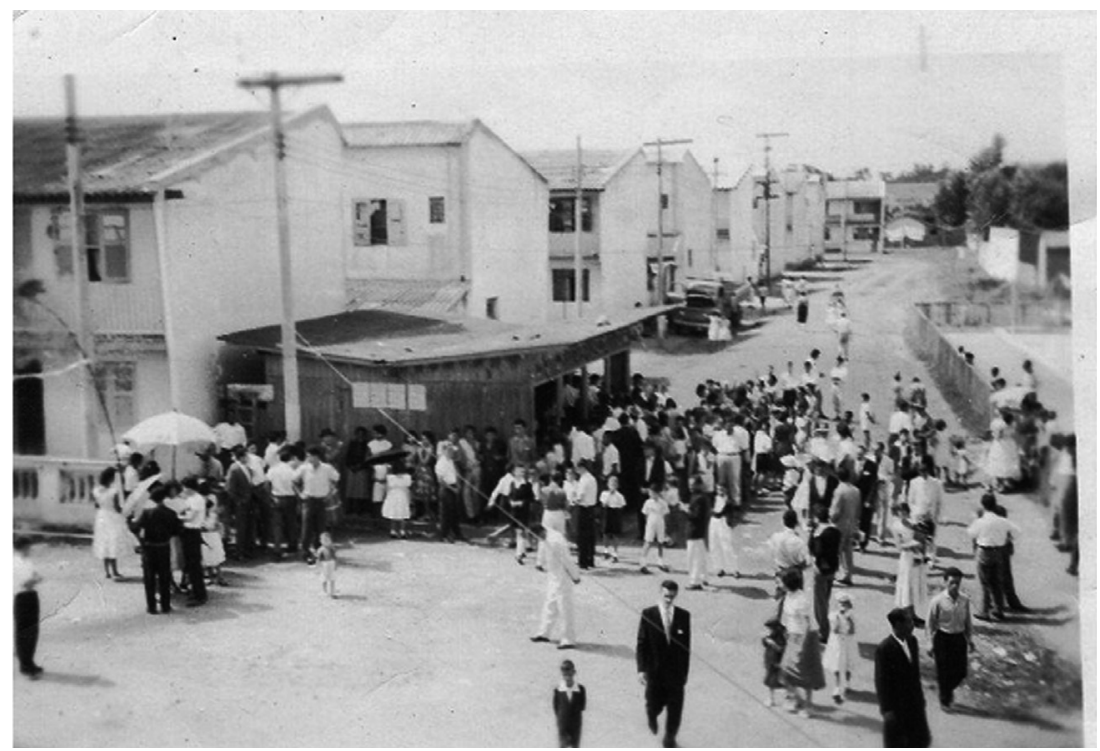

Foto 1. Vila Popular durante confraternização da década de 60. Acervo de Airton Maldonado Romero, colaborador deste projeto, morador da Vila Popular no Bairro Santa Terezinha.

Os sobrados tinham originalmente $3,75 \mathrm{~m}$ por $10 \mathrm{~m}$ e quintal de $16 \mathrm{~m}^{2}$, dois quartos e banheiro na parte superior e sala cozinha e quintal na parte inferior. Hoje alguns foram alterados e outros completamente demolidos para a construção de uma nova casa, porém no mesmo lote. A vila foi projetada originalmente para operários da região, mas muitos ferroviários se instalaram lá. Em sua composição original, podemos perceber o fenômeno da migração interna, pois muitos dos moradores vieram do interior de São Paulo, atraídos pela oportunidade de emprego das indústrias do $\mathrm{ABC}$ e também devido à crise cafeeira. $^{1}$

Antonio Torrente Lopes e esposa, Tereza Torrente Lopes, eram moradores das casas populares no bairro Santa Terezinha. O senhor Antonio trabalhava na área jurídica, era funcionário do Sesi e lá prestava assistência gratuita a moradores de Santo André. Ele conta que o Sesi não era onde é hoje, perto da estação ferroviária prefeito Saladino. Diz que era espalhado pela cidade e

1 Fonte: Projeto "Viva Cidade - subsídios históricos, a ocupação do vale do Tamanduateí". Este projeto de 1990, no que se diz respeito à ocupação do vale do Tamanduateí, colhe depoimentos de moradores do bairro Santa Terezinha nesta data e também utiliza levantamentos de 1976 e 1984. Prefeitura Municipal de Santo André, 1990. Disponível no Museu de Santo André. 
que inclusive possuía salas junto ao clube da Rhodia, que ficava onde hoje está localizado um supermercado de uma grande rede. Sua família veio do bairro Ipiranga, cidade de São Paulo, para as casas populares em 1948, quando ele ainda era criança. Antonio conta que as ruas eram de terra, não havia iluminação, o transporte para Santo André era feito por um ônibus que vinha do Camilópolis. Todos na vila se conheciam. No local onde hoje está a praça João Rosa havia um grande salão de festas que era usado gratuitamente pelos moradores. O escritório da empresa que loteou o local ficava embaixo dele e era lá que os moradores iam pagar as prestações dos imóveis. O salão deixou de existir depois da criação do Clube Ouro Verde, que chegou a administrá-lo por pouco tempo.

Ao contarem um pouco de si e do próprio bairro, cada idoso ao narrar suas lembranças sobre os lugares não está apenas construindo suas memórias particulares, mas a memória coletiva do grupo, compartilhavam lembranças em comum, sobre bailes, clubes, cinemas, aspectos do bairro, entre outros, gerando assim uma conversa descontraída como quando entre amigos.

Essa articulação entre a memória individual e coletiva é explicada por Halbwachs (1990), que entende a memória como resultado da relação dos indivíduos em seus grupos sociais. Ao invés de estudar a memória em si, isolando no indivíduo e colocando-a cada vez mais distante do social, Halbwachs propõe-se a analisar os "quadros sociais". A lembrança individual passa a estar relacionada com os grupos e instituições às quais o indivíduo pertence, sendo estes a família, a classe social, a escola, a igreja ou o trabalho. Diante disso, o que se percebe é que quando lembramos é porque os outros, a situação presente, nos fazem lembrar, pois na maior parte das vezes, lembrar não é reviver, é refazer, reconstruir, repensar, com imagens e ideias de hoje as experiências do passado. Este autor considera que a menor alteração do ambiente atinge a qualidade da memória e amarra a memória da pessoa à do grupo; e, ainda, que a linguagem é o instrumento decisivamente socializador da memória.

Ainda hoje muitos dos moradores iniciais ou seus descendentes moram na vila, mas há uma tendência visível da saída de seus antigos moradores de lá. Casas estão sendo reformadas para aluguel, pois em 2006 a Universidade Federal do ABC (UFABC) iniciou suas atividades no bairro Bangu, o que provocou a demanda por repúblicas na região e também o aumento significativo do valor financeiro dos imóveis.

Muitas são as narrativas sobre o local onde se situa hoje a Universidade Federal do ABC. Maria Helena, moradora do bairro Bangu, recebeu-nos em sua casa. Conversamos durante um bom tempo com ela, vimos fotos antigas 
e servindo-nos de refrigerante e bolo, oferecidos por ela. Contou-nos sobre os múltiplos usos do terreno da universidade, antes dela ser construída ali. Contou que na rua Santa Adélia, antes da curva com a rua Abolição, ruas que ladeiam a universidade, havia a casa de uma senhora muito conhecida na região por ser benzedeira. Era conhecida por "vó preta" e morava em uma casa de dois cômodos com outras pessoas. Esta senhora tinha grande afeição por dois pés de abacate plantados próximos à sua casa, por terem sido plantados por seu falecido filho. Os pés de abacate continuam no local.

Contou ainda que no terreno onde agora é o campus da universidade, na rua Santa Adélia, havia um abrigo para crianças chamado "Lar menino Jesus", e que em época de enchentes, que já eram e ainda são comuns ali, as crianças ficavam por alguns dias nas casas dos moradores próximos esperando a situação voltar ao normal. Devido às enchentes, a casa mudou-se para outra localidade de Santo André. Antes disso, nos anos 1950, época em que a coleta de lixo de Santo André era feita por carroças, no local onde está a entrada da rua Santa Adélia funcionava uma cocheira, para os cavalos que puxavam as carroças. Nesta época, o terreno ainda não era murado, sendo separado da rua apenas por cercas de madeira e arame farpado. Anos mais tarde, o local tornou-se garagem municipal para veículos da prefeitura. Ali havia grandes galpões que abrigavam anualmente a "Feira da fraternidade" que acontecia em maio e reunia grande parte da população de Santo André. No local, funcionava um parque de diversões.

As narrativas sobre o bairro não constituem uma descrição objetiva dos lugares, eventos, mas é permeada dos significados atribuídos pelos narradores. Assim cabe ao pesquisador interpretar as narrativas para compreender os contextos sociais em que se produzem as narrativas bem como as posições sociais dos narradores. Vejamos como Weller (2010b, p. 291) concebe a interpretação:

Em outras palavras: as abordagens qualitativas não trabalham com campos 'recortados' ou 'medidos' de forma objetiva, mas com construtos sociais, cuja importância só será reconhecida no processo interativo de pesquisa e de interpretação dos dados coletados. Ao invés da compreensão hermenêutica dos 'níveis espirituais' (Seelenzustände), a interpretação hermenêutica no âmbito das metodologias qualitativas atuais busca reconstruir os processos interativos, que produzem o 'sentido prático' ou a construção social da realidade (Köller, 2003).

As narrativas em análise não são propriamente biográficas, mas narrativas de idosos sobre algumas experiências de suas vidas. São, portanto, 
fragmentos e memórias de suas trajetórias de vida. Apesar disso, entendemos que as orientações metodológicas de Weller (2010a; 2010b) e de Fanton (2011), ambas inspiradas em Fritz Schütze, são adequadas para a interpretação das narrativas anteriormente descritas.

Observamos que na narrativa do bairro, no trabalho da memória, os idosos narram sobre a construção das "casas populares", com ruas de barro, sem iluminação e sem transporte público. Qual sentido tem essa narrativa em relação às suas experiências anteriores e à atual? As casas foram construídas no final da década de 1940, período em que o município de Santo André e os outros municípios da região do $\mathrm{ABC}$ emergem como enquanto região industrial, com uma concentração de empresas automobilísticas. Levas de trabalhadores chegaram do interior de São Paulo, Paraná e de estados da região Nordeste, além da população já residente no município, cuja origem era de imigrantes europeus. Trata-se da década de formação da classe trabalhadora urbana, em especial, do operariado industrial e as empresas precisavam tanto de uma quantidade de força de trabalho disponível quanto de sua estabilidade na região. $\mathrm{O}$ acesso a uma casa própria favorecia o empresariado que teria uma força de trabalho disponível e estável. Mas para os trabalhadores representava a concretização de um sonho, pois lhe permitiria garantir um porto seguro para a família e a formação de um patrimônio. A narrativa da senhora Maria Aparecida de Paula Vicente Silvério, 79 anos, moradora das casas populares indica que a aquisição da casa na Vila Popular representou uma melhoria de moradia e certa ascensão social, em relação à casa anterior que era de chão de barro. A narrativa sobre as casas populares conecta-se também com o tempo presente, se no início de suas vidas ou de seus pais foram morar em casas populares projetadas para operários, atualmente todos os idosos que participaram dos encontros na universidade são proprietários de suas casas e os que ainda moram na Vila Popular foram ao longo da suas trajetórias de vida modificando-as, seja ampliando ou reformando com novos materiais como pisos de cerâmica. Assim, a narrativa das casas populares pode ser compreendida como um símbolo de uma trajetória de ascensão social, mesmo considerando que não tenha ocorrido alteração do pertencimento de classe, ou seja, de classe operária.

\section{Memórias do lazer e do esporte}

Além da roda de conversas, utilizou-se como metodologia para estimular o trabalho de memória a exposição de documentários de época sobre lugares e eventos do município. Em um dos encontros foi passado um filme com imagens do centro da cidade de Santo André na década de 50, e sugeriu-se que 
os idosos reconhecessem e comentassem sobre as imagens e as lembranças que elas traziam. Essa atividade rendeu muitos relatos e observações interessantes, alguns se emocionaram com as imagens mostradas, lembrando seus tempos de juventude. Foi proposto que cada um falasse suas impressões e memórias, e muitos comentaram sobre os trajes da época, alguns homens repararam nos modelos dos carros, mas chamou a atenção, particularmente, o comentário feito pela dona Teresa $\mathrm{T}$. Lopes, que referiu-se à tranquilidade das pessoas nas ruas e seu saudosismo dos tempos em que se andava tranquilamente pelas vias, sem a pressa e a tensão cotidiana vivida atualmente. Foi muito citado também o cinema, já que o curta mostrava em uma de suas cenas, a imagem do antigo cinema Tangará, frequentado por muitos dos idosos presentes. Segundo eles, o cinema era um dos principais entretenimentos, além do flerte que ocorria na saída das sessões, onde, segundo eles, não existia a malícia atual. O vídeo rendeu muitos relatos engraçados e curiosos, os quais foram todos registrados para posterior edição e análise.

Nas rodas e conversas assim como nas entrevistas realizadas nas residências dos idosos, a memória dos moradores dos dois bairros não se refere apenas às casas, infraestrutura do bairro, ou ao trabalho, mas também às suas experiências de sociabilidade, em especial às relativas às práticas de esporte, como podemos observar no depoimento do senhor Farid Nasser Chedid.

Ah, sim. Eu fui campeão paulista, eu fui da seleção paulista de voleibol. Aqui o primeiro clube foi o Clube Rhodia, porque antes de entrar na Rhodia, eu jogava no Clube Rhodia. E por que eu jogava no Clube Rhodia? Porque os bailes, os melhores bailes que tinham na cidade, eram feitos nos ginásios da Rhodia, então eu entrei para jogar para ser sócio militante, porque aí eu não pagava, eu tinha a carteirinha do clube e podia frequentar os bailes.

[...] Nós fomos campeões paulistas de voleibol na Rhodia. Depois a Rhodia transformou o clube numa ADC, que era Associação Desportista Classista, que foi uma regulamentação que houve, e ai o clube passou a ser só de sócios, só de empregados. E eu como não era empregado... Toda a equipe de voleibol saiu da Rhodia, tinha uma boa equipe de voleibol, tinha uma boa equipe de basquete também. E essas equipes sairam porque já não podiam ficar na Rhodia. Então a Rhodia desativou essa parte mais esportiva. Ai vinha uma empresa têxtil aqui chamada Randi, que absorveu o time de voleibol, en joguei mais um pouco pelo Randi, pela seleção de Santo André. Em 58 teve os Jogos Abertos em Santo André. Ai depois eu desativei um pouco, porque ai eu comecei a estudar na faculdade e ai não dava mais para conciliar o trabalho, o estudo em faculdade e jogar voleibol. 
A narrativa do senhor Farid pode ser compreendida como uma "narração biográfica" nos termos descritos por Marcos Fanton (2011, p. 531):

Compreendemos que toda narração possui, basicamente, cinco características principais: [a] uma característica temporal: a narrativa é a representação de eventos passados a partir de uma perspectiva atual; [b] uma característica social: a situação na qual ocorre a entrevista é uma situação social, que irá influenciar o modo de narração do indivíduo. Ou seja, o discurso deste é um discurso para uma audiência específica; [c] uma característica significativa: a narrativa expressa o significado dado pelos indivíduos à suas experiências e situações passadas, assim como da sua vida (biografia) como um todo; [d] uma característica subjetiva: a narrativa é sempre a expressão da perspectiva de um indivíduo cuja biografia é única e singular; [e] uma característica linguística: a narração é realizada a partir da linguagem cotidiana do indivíduo, quer dizer, da linguagem que lhe é mais familiar e rotineira.

Voltando ao fragmento de Farid Nasser Chedid, sua narrativa é uma representação de fatos passados a partir da sua posição no ciclo de vida atual. Ao exaltar a participação como jogador e campeão na Rhodia e nos Jogos Abertos de Voleibol de Santo André, ele constrói um demarcador de sua identidade de esportista que contrasta com a sua condição atual de idoso. Esse é um discurso produzido para uma audiência específica, no caso o entrevistador que está em interação presente com o seu corpo de idoso. Essa nova forma de expressão do corpo começa a ser identificada com a frase: "Aí depois eu desativei um pouco, porque aí eu comecei a estudar na faculdade e aí não dava mais para conciliar o trabalho, o estudo em faculdade e jogar voleibol."

A característica subjetiva está presente na narrativa, a imagem de um corpo para o esporte é enfatizada. Ele deixa o esporte devido a motivos exteriores como trabalho e faculdade e não devido à fragilidade de seu corpo e sua habilidade esportista. Mas a narrativa de Farid também mostra a intersecção entre uma biografia individual e coletiva, ou nos termos de Halbwachs (1990), entre a memória individual e a coletiva. O fragmento da fala do senhor Farid abaixo ilustra essa ideia:

[...] Então você tinha o cinema de sábado e de domingo, que é um programa, eu tinha o esporte que eu fazia durante a semana, e às vezes domingo de manhã, e na época o bom era baile. Então tinham muitos bailes de formatura, bailes domingueiras, matinês etc.. Tinha tudo isso. E a gente frequentava e dançava. Ai depois que a Rhodia... a Rhodia continuou durante um certo tempo, até, dominando os bailes, porque a maioria dos bailes de formatura eram feitos lá, porque era o primeiro ginásio coberto que tinha 
em Santo André. Ai se inaugurou aqui o Moinho São Jorge, que foi um desbunde total na época, porque eles fizeram no último andar um salão de festas enorme que se chamava Palácio de Mármore. É um negócio fantástico. Tem até hoje, só que eles não usam mais como salão. E ai os bailes de formatura passaram a ser no Moinho São Jorge.

Observamos que ele se refere aos bailes do Moinho São Jorge. Em entrevistas com moradores do bairro, muitas são as histórias dos bailes nesse Moinho. Alguns contam que para entrar sem pagar subiam até o $8^{\circ}$ andar, onde está localizado o salão, pelo elevador de carga, o mesmo que transportava os sacos de farinha. Assim, ao chegar lá, esses aventureiros tinham que limpar o paletó que ficava todo branco de farinha.

Além dos bailes, também há narrativas sobre os fletes e namoros nas praças. Antônio casou-se com sua vizinha Tereza. Ela conta que naquela época era muito comum os jovens irem para a praça flertar, neste caso, era praça Rui Barbosa em Santa Terezinha. As meninas ficavam de braços dados e andando ao redor da praça e os meninos sentados em grupos. Quando uma menina se interessava por alguém, ela se soltava das amigas e o rapaz ia conversar com ela. Algumas vezes um rapaz poderia levar a menina até próximo de sua casa, mas não podia se aproximar muito. Tereza conta que nessa época em um namoro demorava-se dois meses para o garoto pegar na mão da menina.

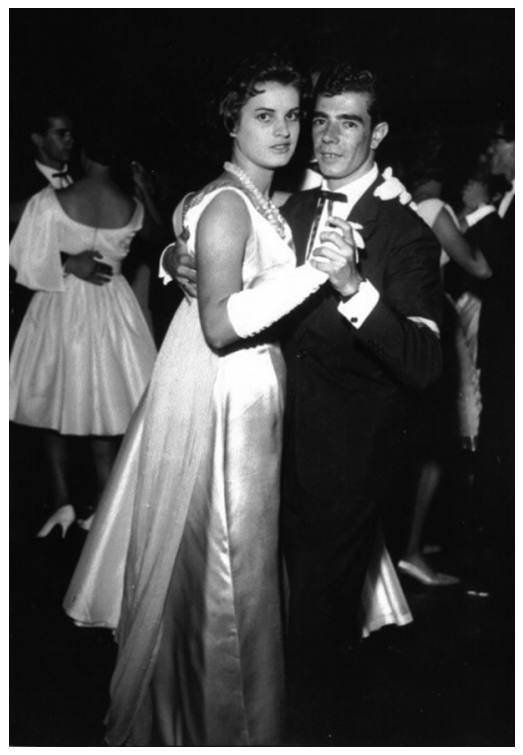

Foto 2. Antonio e Tereza em um dos vários bailes da região. 
Durante todos os encontros, os laços que ali eram construídos faziam com que os idosos trouxessem suas interpretações sobre família e conjugalidade. As mudanças nas formas de se relacionar eram compreendidas de maneiras diversas entre estes sujeitos, que sobretudo se lembravam de seus filhos e netos ao se aproximarem dos estudantes participantes do projeto. Não obstante, as memórias que traziam no que tange à noção de família também era mobilizada em função das trocas de experiências entre os idosos, de como eram as paqueras, os namoros, quais eram o truques para escapar da supervisão dos pais. Entre fotos e documentos, muitos trouxeram fotos e cartas de amor. As fotos, sempre marcadas por situações especiais e poses de retrato, recordavam-nos do primeiro amor e das primeiras paqueras, de modo que teciam comentários e narrativas costuradas numa relação comparativa com o presente.

As narrativas sobre esporte e os bailes indicam as práticas de sociabilidade entrecortadas entre o tempo do trabalho e do lazer. Os esportes podiam ser praticados durante a semana, mas os bailes só nos finais de semana. Embora não tenhamos narrativas que tenham desenvolvido mais extensamente sobre a relação entre tempo de trabalho, esportes e bailes e cinemas, os fragmentos trazem indícios da estrutura de dominação das fábricas sobre o tempo, o corpo e os espaços dos trabalhadores. O esporte provavelmente poderia ser praticado durante a semana porque disciplinava o corpo dos trabalhadores tanto em termos físicos quanto do desenvolvimento da obediência à posições superiores. Já os bailes e cinema se situam no tempo do ócio, do extraordinário, do informal, da sociabilidade lúdica, em que as interações sociais os amigos e parentes são fundamentadas no prazer, na dádiva e não no dever de exercer atividades sob mando de agentes em posições superiores. Essas narrativas, embora individuais, expressam fragmentos da experiência social dos operários dos dois bairros estudados.

\section{Considerações finais}

As narrativas analisadas nesse artigo resultaram das interações entre idosos -homens e mulheres-e famílias operárias de dois barros do município de Santo André e jovens estudantes de graduação e professores da também jovem Universidade Federal do ABC, inaugurada em 2006. Gostaríamos de tecer algumas reflexões sobre as interações sociais que envolvem sujeitos em posições sociais diferenciadas. Nas conversas individuais, nos encontros semanais e nas entrevistas realizadas nas residências notamos uma boa receptividade dos idosos, o que além do que podemos chamar de boa educação e simpatia, reflete a carência deste grupo social em ser ouvido. Eles, muitas 
vezes, não encontram pessoas dispostas a ouvi-los, a dar atenção às tantas histórias que querem ser contadas. O gesto dos estudantes e professores de dedicação e atenção propiciaram aos idosos criarem laços de amizade e de confiança. Poderíamos dizer, nos termos de Goffman (1985, p. 18-19), que nas interações entre os professores, estudantes e os idosos havia interesses mútuos, de modo que se construía um consenso operacional. Também observamos práticas de reciprocidade com trocas de saberes, informações e alimentos, saberes. Havia um sentimento de gratidão por parte dos idosos, que como forma de retribuição, decidiram trazer-nos bolos e pães para os lanches. Na verdade, ambos os lados são beneficiados pela troca mútua de experiências e histórias de vida de diferentes gerações. Se havia um consenso operacional, ele não eliminava as diferenças entre os idosos e os estudantes e professores. Nesses termos concordamos com Bourdieu (1999) que entende que as interações sociais são permeadas por relações de poder, mas podem, também, se constituir em um espaço de negociação de identidades, saberes, concepções, possibilitando situações de empoderamento dos informantes. A construção desse espaço depende, em grande medida, da relação do(a) pesquisador(a) com o outro. Como nos ensina Portelli (1997, p. 17): “o respeito pelo valor e pela importância de cada indivíduo é, portanto, uma das primeiras lições sobre a experiência com o trabalho de campo na história oral". O respeito ao outro não é um pressuposto nem um resultado do processo de pesquisa mas consiste em um exercício epistemológico, em que se busca aprimorar a arte de ouvir e de dialogar. Como nos ensina Portelli (1997, p. 22), a arte de ouvir não significa, no entanto, uma igualdade entre os sujeitos em interação social, mas antes, o reconhecimento da diferença e a busca da igualdade. A diferença de posições sociais entre os idosos, estudantes e professores não resultou em um diálogo entre iguais, mas mistura, amalgama, envolvendo, portanto, a construção de consensos, respeito mútuo, valorização de saberes e tecnologias.

\section{Referências}

BOSI. Ecléa. Memória e sociedade: lembranças de velhos. São Paulo: Companhia das Letras, 1987.

BOURDIEU, P. A juventude é apenas uma palavra. In: Pierre Bourdieu. Questões de sociologia. Rio de Janeiro: Marco Zero, 1983.

BOURDIEU, P. A miséria do mundo. 3. ed. Petrópolis: Vozes, 1999.

FANTON, Marcos. Sujeito, sociedade e linguagem: uma reflexão sobre as bases teóricas da pesquisa com narrativas biográficas. Civitas, v. 11, n. 3, p. 529-543, 2011.

GOFFMAN, Erving. A representação do eu na vida cotidiana. Petrópolis: Vozes, 1985. 
HALBWACHS, M. A memória coletiva. São Paulo: Vértice, 1990.

KÖLLER, Hans-Christoph. Hermeneutik. In: Ralf Bohnsack et al. (Orgs.). Hauptbegriffe Qualitativer Sozialforschung: ein Wörterbuch. Opladen: Leske und Budrich, 2003.

MANNHEIM, K. Structures of thinking. London: Routledge \& Kegan Paul, 1980.

MILLS, W. A imaginação sociológica. 4a . ed. Rio de Janeiro: Zahar, 1975.

OLIVEIRA, Roberto Cardoso de. O trabalho do antropólogo. $2^{\mathrm{a}}$ ed. São Paulo: Editora Unesp, 2006.

POLLAK, Michel. Memória, esquecimento, silêncio. Estudos Históricos (Memória), v. 2, n. 3, p. 3-15, 1989.

PORTELLI, A. Tentando aprender um pouquinho: algumas reflexões sobre a ética na história oral. Projeto História, v. 15, p. 13-49, 1997.

WELLER, Wivian. Grupos de discussão: aportes teóricos e metodológicos. In: Wivian Weller e Nicolle Pfaff (Orgs.). Metodologias da pesquisa qualitativa em educação: teoria e prática. Petrópolis: Vozes, 2010a, p. 54-66.

WELLER, Wivian. Aportes hermenêuticos no desenvolvimento de metodologias qualitativas. Linhas Críticas, v. 16, n. 31, p. 287-304, 2010 b.

Recebido em: 10 set. 2013

Aprovado em: 14 abr. 2014

Autora correspondente:

Marilda Aparecida de Menezes

UFABC - Universidade Federal do ABC

Av. dos Estados, 5001 - Bairro Bangu

09210-580 Santo André, SP, Brasil 